Journal of Social Sciences 1 (3): 194-196, 2005

ISSN 1549-3652

(C) 2005 Science Publications

\title{
The Quality of Homeland Security and Health Care Systems: The Texas Rangers Initiative
}

\author{
Eldo Ermenegildo Frezza and Maurizio Chiriva-Internati \\ Texas Tech. University Medical Center, Lubbock TX and Texas Medical Rangers, USA
}

\begin{abstract}
Healthcare facilities are an essential component of an emergency response system in case of nuclear, biological or chemical attack, but at the present time, are poorly prepared for an incident. Key elements of the healthcare facility response plan include prompt recognition of the incident, staff and facility protection, patient decontamination and triage, medical therapy, and coordination with external emergency response and public health agencies. Controversial aspects include the optimal choice of personnel protective equipment, establishment of patient decontamination procedures, the role of chemical and biological agent detectors and potential environment packs and water treatment systems. The medical profession must assume a central role in state and national organizations, such as the Texas Rangers Medical Corps. The Texas Rangers Medical Corps shows a possible system to set security plans, policies and systems in each state or region independently, but unified since they can join together to bring each experience to a national coordinated committee.
\end{abstract}

Key words: Homeland security, health care, weapons of mass destruction, terrorist attack, policies

\section{HOMELAND "INSECURITY"}

Osama bin Laden highlighted the connection between American military power and its economy in his first fatwa in the late 1990's ${ }^{[1]}$ Jihad against Jews and Crusaders," he called on every Muslim to kill Americans and "plunder their money wherever and whenever they find it". After 9/11, they effectively blocked our own economy.

The new security plan should take the appropriate steps to reduce the risk that would allow destruction of the things that we value, starting with our economy. It involves improving the capacity to monitor the systems and to develop options, alternative first response plans and policy.

While there cannot be a one plan that fits everyone, there should at least be agreement on minimal communications, equipment, and training capabilities.

\section{HEALTH PUBLIC PROBLEMS}

Public health officials are increasingly worried that weak public confidence in official guidance will undermine their efforts to impose quarantines in the face of, not only bioterrorist attacks, but also of outbreaks of SARS and other naturally occurring diseases. To ensure the nation's approach to homeland security will be as dynamic as the threat that confronts us, local, regional and state authorities should be encouraged to build their own system. Hospitals and healthcare systems should be doing the same. An attack with a nuclear, chemical, or biological weapon will affect not only those who are immediately exposed, but could also wipe out the emergency response and medical care system in the surrounding areas.

\section{THE HEALTH CARE SYSTEM TASKS}

Several federal programs have been initiated to assist communities in enhancing their preparedness for events involving biological or chemical weapons of mass destruction. Community preparedness is far from perfect. Local healthcare, emergency care, EMS, law enforcement and the FBI have been trying to implement responses for possible disaster planning. Improved real time regional patient healthcare capacity. Development of an affordable and accurate biological agent detection system, incorporation of standard education and training curriculum on terrorism and biological agents into healthcare training programs, and expansion of federal and state programs to assist communities in developing increased public awareness and educational programs have increased, particularly after the September 11.

Weapons of mass destruction (WMD) keep every state in every country vulnerable. It is a significant challenge to prepare for an event without a clear-cut indication of whom to protect, when to protect them, and from whom to protect them. In our previous report ${ }^{[2]}$ we reported the problems with healthcare and the need for active plans and policies to apply to healthcare, which includes the Emergency Medical system (EMS) response to the full treatment and decontamination in emergency rooms and hospitals.

\section{HOSPITAL BASED PLANNING}

Healthcare facilities are an essential component of an emergency response system but, at the present time, are

\section{Corresponding Author:}

Eldo Ermenegildo Frezza MD, MBA, Division of General Surgery, Texas Tech University Health Science Center, MOP Building, Suite 380, $35029^{\text {th }}$ Street, Lubbock Texas 79415, Tel: 806-743-4666, Fax: 806-743-4670 
poorly prepared for an incident ${ }^{[3]}$. The greatest challenge may be the sudden presentation of a large number of contaminated individuals. Gathering information on contaminated patients has been based on traditional collection of material response with military experience, neither of which is directly applicable to the civilian.

Key elements of the healthcare facility response plan include prompt recognition of the incident, staff and facility protection, patient decontamination and triage, medical therapy, and coordination with external emergency response and public health agencies. Controversial aspects include the optimal choice of personnel protective equipment, establishment of patient decontamination procedures, the role of chemical and biological agent detectors and potential environment packs and water treatment systems ${ }^{[4]}$.This all needs to be done to improve our response strategies.

The fundamental precept in hospital-based planning for bioterrorism events includes having a comprehensive emergency room disaster plan that is based on threat and vulnerability analysis. The JCAHO environmental healthcare standards and approach to disaster planning and management form the basis for a solid bioterrorism response plan. Preparation, education and training are imperative. Clinicians must maintain a high index of suspicion for use of bioterrorism agents, be able to make a rapid diagnosis and probably initiate empirical treatment. However, the personnel, fellow administration, security, public relations, laboratory, pharmacy and facility management should be familiar with the plan and know when to activate it ${ }^{[4]}$. A recognized incident command system should be used. Hospital leadership must be aware of facility capabilities and capacity and should have plans for expansion of service to meet the surge in demand. The command center should coordinate the emergency personnel teams, decontamination, security, acquisition of supplies and notification of public health and other authorities and the media. If the plan is implemented, stress management and psychological support will play an important role in recovery ${ }^{[5-7]}$.

\section{HEATLHCARE SYSTEM: PART OF THE COMMUNITY}

Chemical warfare agents as a military issue ${ }^{[8]}$ are events and civilians could be exposed to these agents. Weapons of mass destruction (WMD) are threats that all healthcare facilities must be prepared to handle ${ }^{[9]}$. Every healthcare facility is a vital part of the community response system and must be ready to respond. Private vehicles or busses might transport the majority of patients, with only a small percentage arriving by emergency medical service. Most will go to the hospital closest to the incident, even if it results in overcrowding. Others will go directly to their private physician's office or primary hospital even if these facilities are not part of the local disaster plan. Most of these victims will not be decontaminated before arrival. It is important to remember that in most cases of biological or chemical attacks, the victim will be unaware of what is causing their illness. Therefore, they will not be able to alert medical professionals. If the hospital allows any of these patients inside, the staff may exposed to the toxin, and the facility may require closure for decontamination. The risk is universal. The healthcare facility must plan for communication that allows local government to transmit alerts regarding the emergency. Healthcare facilities must also communicate the status of the emergency needs to local officials during the emergency. In order to limit contamination, the facility must be prepared to establish a single entry control point and attempt to secure all other entrances. The ability to establish a patient decontamination team from on-duty staff with only a few minutes notice at any time of the day or night is vital.

\section{HEALTHCARE WMD PLANS}

A schematic WMD plan is reported in Table 1. In general, the absolute requirement for implementation of WMD response: 1) policy, 2) plan, 3) emergency department response to surge capacity, including design of emergency department, equipment required, personnel required, education and training, occupational health and safety issues, and surveillance system in details. WMD policies and plans were described by our group in an earlier publication ${ }^{[4]}$.

Table 1: Schematic WMD Healthcare plan

WMD Implementation

Policies

Plans

Ambulance traffic

Personal protective equipment

Training personnel

Personnel requirements

Education

Treatment

Surveillance system

Decontamination system

\section{THE COST OF SECURITY}

The task force of the Council on Foreign Relations was co-chaired by former Senators Gary Hart and Warren Rudman ${ }^{[10]}$ reported that America remains dangerously unprepared to prevent and respond to a catastrophic attack on U.S. soil.

Security is not free. Healthcare incurs costs. Dollars spent on security could effect local people who need the most, and some hospitals do not have deep enough pockets to change and add security systems. 


\section{EACH STATE'S OWN DEFENSE}

Each state needs to step up in homeland security. The United States is composed of different states. Each state needs to help Washington by setting up a security committee. A member from each state committee should be part of a national committee which meets in Washington to report each state's experiences and to develop a full, well expanded homeland security. This might help optimize the status of homeland security. Organizations, such as the Texas Rangers, are implementing organizations and policies and plans to protect the state of Texas, establishing the standard for homeland security. The Corps will work towards the construction of a homeland security plan for the state of Texas in hopes of increasing and setting new standards. If this works, it might also be adopted by the members of the European Union.

\section{THE TEXAS RANGERS MEDICAL CORPS}

The Texas Rangers are a well known Corps under the direct supervision of the Texas Governor. This Corps became famous with movies starring Charles Bronson more than 20 years ago. This Corps has remained active and formed by independent personnel who are soldiers, enforcement officers and other volunteers.

Texas is divided into six regions. Each region has a commander to build their own Texas Rangers Medical unit. The medical units are formed by physicians, nurses, psychiatric technicians, EMS and all paramedics associated with the hospital. All of these are volunteers and in some areas, they are experts of homeland security, particularly nuclear, biological and chemical attacks.

The idea was to form a group that, when it was needed, could be called by the governor to help in the coordination or in providing help to the county or city in the case of a terrorist attack. The idea is interesting because it provides physicians' and nurses' expertise to areas in Texas where there is no expertise in homeland security; therefore, it could be a good referral base in case the city or county has problems.

This could be applied to each state, each state could have a well formed, dependable system which could step up to the plate and help when inland or terrorist attack problems occur.

The federal government should think about instituting a Corps in each state under federal government supervision.

\section{CONCLUSION}

The medical profession must assume a central role and participate actively in the discussion and planning strategies in order to influence formulation of policy that will activate in response to bioterrorism events by conglomerating in organizations such as the Texas
Rangers Medical Corps. This policy must integrate the various activities and interest of federal and local government agencies, law enforcement, fire departments and other agencies involved in reaction to a massive bioterrorism attack. One of the possible solutions suggested by the Texas Rangers Medical Corps initiative is to set security plans, policies and systems in each state or region which can join together to bring each experience to a national coordinated committee.

\section{REFERENCES}

1. World Islamic Front Statement, 1998. Jihad Against Jews and Crusaders.

2. Frezza, E.E., 2004. The challenge to hospitals and health care systems preparing for WMD. ACMQ Focus, 14: 11-12.

3. Macintyre, A.G., G.W. Christopher, E.Jr. Eitzen, R. Gum, S. Weir, C. DeAtley, K. Tonat and J.A. Barbera, 2000. Weapons of mass destruction events with contaminated casualties: Effective planning for health care facilities. JAMA., 283: 242-9.

4. Frezza, E.E., 2005. The challenge of the hospitals \& healthcare systems in preparation for biological and chemical terrorism attack. J. Social Sci., 1:19-24.

5. Schultz, C.H., J.L. Mothershead and M. Field, 2002. Bioterrorism preparedness. I: The emergency department and hospital. Emerg. Med. Clin. North Am., 20: 437-55.

6. McFee, R.B., 2002. Preparing for an era of weapons of mass destruction (WMD). Are we there yet? Why we should all be concerned. Part 1. Vet. Hum. Toxicol., 44: 193-9.

7. Flowers, L.K., J.L. Mothershead, T.H. Blackwell, 2002. Bioterrorism preparedness. II: The community and emergency medical services systems. Emerg. Med. Clin. North Am., 20: 457-76.

8. Brennan, R.J., J.F. Waeckerle, T.W. Sharp and S.R. Lillibridge, 1999. Chemical warfare agents: Emergency medical and emergency public health issues. Ann. Emerg. Med., 34: 191-204.

9. Bradley, R.N., 2000. Health care facility preparation for weapons of mass destruction. Prehosp. Emerg. Care, 4: 261-9.

10. Council on Foreign Relations Task Force Report: Emergency Responders: Drastically Underfunded, Dangerously Unprepared, Report of an Independent Task Force (New York: Council on Foreign Relations, July 2003). 